\title{
Eventos esportivos: do Big Brother ao Brecht Brother
}

Sports events:

from Big Brother to Brecht Brother

Eventos deportivos: del Big Brother
al Brecht Brother

Hugo Rodolfo Lovisolo

- Doutor e mestre em Antropologia Social pela Universidade Federal do Rio de Janeiro (UFRJ)

- Pós-doutorado em Ciências dos Esportes pela Universidade do Porto (Portugal)

- Graduado em Sociologia pela Universidad de Buenos Aires

- Professor adjunto da Universidade do Estado do Rio de Janeiro (Uerj) e do Mestrado em Desenvolvimento Social do Centro Universitário Augusto Motta (Unisuam)

- Coordenador do Grupo de Esporte e Cultura - Uerj/CNPq

- Autor de Estética, esporte e educação física; e Educação física: arte da mediação

- Organizador da obra Motus corporis (11. ed.) e co-organizador de, entre outras obras: Esporte de rendimento e esporte na escola; $A$ invenção do país do futebol

- Tem experiência na área de antropologia e sociologia da ciência, educação, educação física, ciências dos esportes, com ênfase nos seguintes temas: comunicação e jornalismo esportivo, cultura, educação e desenvolvimento local.

-lovisolo@globo.com 
Neste ensaio, o autor aproveita a oportunidade dos megaeventos que serão realizados no Brasil para relacionar os espetáculos esportivos à crítica paralela da democracia e da falta de participação com atividade e criatividade enquanto temas centrais do desenvolvimento sustentável e inclusivo, do capital social e da confiança e geração de arranjos produtivos e sociais. No cruzamento de corpos teóricos de histórias específicas, de críticas e propostas, o autor sugere que o campo dos megaeventos poderia se constituir em objeto tanto de análise do capital social e da confiança quanto de sua geração. Sugere também que as áreas da comunicação social e da educação física poderiam desempenhar um papel relevante no campo da geração do conhecimento tanto sobre os problemas em pauta, quanto sobre práticas institucionais, esportivas e comunicativas, contribuindo para a ampliação do capital social e da confiança.

PALAVRAS-CHAVE: ESPETÁCULO ESPORTIVO • COMUNICAÇÃO • CAPITAL SOCIAL • CONFIANÇA

\section{Abstract}

In this essay, the author uses the opportunity of the mega-events that will be held in Brazil to relate the sports spectacles to the simultaneous criticism of the democracy and of lack of involvement and creativity as central themes of sustainable and inclusive development, social capital, trust and generation of productive and social arrangements. At the intersection of theoretical approaches of specific stories, criticism and proposals, the author suggests that the field of mega-events could be both subject-matter of analysis of social capital and trust and their own generator. The author also suggests that the areas of social communication and physical education could play a relevant role not only in the field of generation of knowledge about such problems, but also in sports, institutional and communicative practices, contributing to the increase of social capital and trust.

KEYWORDS: SPORTS SPECTACLE • COMMUNICATION • SOCIAL CAPITAL • TRUST

\section{Resumen}

En este ensayo, el autor aprovecha la oportunidad de los megaeventos que tendrán lugar en Brasil para relacionar los espectáculos deportivos con la crítica paralela a la democracia y a la falta de participación de forma activa y creativa como ejes centrales del desarrollo sostenible e inclusivo, del capital social y de la confianza y generación de acuerdos productivos y sociales. En el cruce de los cuerpos teóricos de historias específicas, de críticas y propuestas, el autor sugiere que el campo de los megaeventos podría ser tanto un objeto de análisis del capital social y de la confianza como de su generación. Sugiere también que las áreas de la comunicación social y la educación física podrían desempeñar un rol relevante tanto en el ámbito de la generación de conocimiento sobre los problemas actuales como en el de las prácticas institucionales, deportivas y comunicativas, contribuyendo así a la ampliación del capital social y de la confianza. 

odemos partir do acordo existente sobre a importância crescente dos eventos esportivos em termos de público, seja como assistente presencial ou direto, seja como assistente midiático predominantemente via televisão. Se a assistência cresceu exponencialmente para os megaeventos, como a copa do mundo de futebol e os jogos olímpicos, seu efeito parece ter-se alastrado, com intensidades diferenciadas, para outros eventos esportivos como o vôlei, a fórmula i, os abertos de tênis, a ginástica olímpica e variados esportes de luta, entre outros.

Os espetáculos esportivos tornaram-se, de forma crescente, loci de investimentos e negócios de estados e particulares. Os espetáculos esportivos podem ser agrupados dentro da categoria mais ampla dos entretenimentos, dos passatempos ou, como afirma Lovisolo (2002), das atividades antitédio. Esse campo de negócios, embora possa ter antecedentes longínquos, sendo o circo romano o caso mais notório, cresceu em importância ao longo dos séculos, beneficiado por inovações tecnológicas, desde a construção civil ao transporte e passando pela comunicação midiatizada.

Creio que sobre esses aspectos não existem muitas dúvidas; eles representam apenas constatações de partida, que são estudadas sob o nome dos efeitos tangíveis dos espetáculos esportivos e não fazem parte de minha preocupação neste ensaio. Concentrar-me-ei no que se convenciona denominar aspectos intangíveis, que serão a matéria-prima de minhas reflexões. Observo que os aspectos ou efeitos intangíveis podem se tornar tangíveis quando elaboramos indicadores que permitem sua qualificação e quantificação. Assim, a denominação "intangível” pode mudar no tempo.

Os efeitos intangíveis possuem um leque consideravelmente amplo na literatura especializada. Reduzirei minha argumentação àquilo que de praxe se reconhece como "confiança social" - dimensão central do capital social mesmo quando entendido como rede de relações -, cujo papel no desenvolvimento social é destacado na capacidade de gerar acordos e criar marcos institucionais para o agir coletivo. Chegarei ao ponto mediante um breve percurso.

\section{A CONSOLIDAÇÃO DO GOSTO PELO ESPORTE E A SUA CRÍTICA}

Podemos deduzir das constatações acima delineadas três aspectos implicados: 1) a ascensão e consolidação do gosto pelo esporte; 2) a adesão ao papel de espectador presencial ou midiático de amplas parcelas da população mundial; e 3) a competição regrada como uma força centrípeta poderosa, ou seja, ela junta até aqueles que não imaginamos que poderiam ser juntados: negros e brancos, visões religiosas em conflito e etnias tradicionalmente em confronto.

Contudo, já faz mais de dois séculos que os que pretendem fazer a humanidade avançar pelo caminho do esclarecimento, da emancipação e do pensamento crítico rejeitam, de modo dominante, o espetáculo esportivo e o espí- 
rito de superação das marcas nas diferentes provas. Os promotores da onda emancipacionista fizeram e ainda fazem um rosário de críticas ao lugar do espectador, às funções de controle atribuídas ao espetáculo e, especialmente, à divisão entre atletas e assistentes. A expressão "sociedade do espetáculo", na trilha aberta por Guy Debord (1992), se tornou uma expressão de crítica tanto ao capitalismo de consumo quanto à democracia representativa. A vida política também passou a ser vista como um espetáculo no qual o poder de comunicar, a representação midiática, ocuparia o lugar do debate de propostas e intenções. A política como espetáculo já estava presente entre os gregos, nas reflexões críticas sobre os demagogos e a retórica.

\section{DA SUBMISSÃO DO ESPECTADOR}

Desde a crítica de Platão às assembleias se entende que os espectadores submetidos aos demagogos, hábeis no uso da retórica, estariam sendo manipulados e levados para finalidades que não são as que talvez devessem seguir. De fato, creio que a crítica platônica, contraditoriamente, abrange os participantes diretos da forma de decisão política mais democrática: a assembleia. Se a forma democrática por excelência é manipulável, restaria apenas a virtude do agir do iluminado bem-intencionado. Todos sabem que a preferência platônica é pelo rei filósofo, virtuoso em intenções e em iluminações.

A crítica platônica parece ter sido estendida para muitas esferas ou instâncias nas quais se manifesta a divisão entre os que falam e os que escutam ou entre os que agem e os que assistem. Na virada do século XIX para o XX, a crítica à divisão formulou-se de modo sistemático no campo da política, mas, mesmo quando mudam os atores na cena, parece persistir algum tipo de divisão, como mecanismo de poder, entre os que mandam e os que obedecem. Os teóricos reconhecidos na categoria de "elitistas" foram responsáveis por elaborar os argumentos explicativos, e até justificativos, para a divisão entre os que governam e os que são governados.

A valorização sempre emergente da democracia direta pode ser entendida como correlata à desvalorização da democracia representativa, que significaria a manutenção da divisão entre os que governam e os que são governados, entre representantes e representados. A representação democrática, para Gaetano Mosca, significava a mudança que permitia não mudar. Os cientistas políticos, agrupados sob o nome de "elitistas", insistiram em apresentar a reprodução da divisão entre governantes e governados enquanto lei de ferro que não podia ser quebrada. Michels e Mosca, entre outros, se caracterizaram pela força que deram a esse argumento, na companhia, nada desprezível, de intelectuais tão díspares quanto Pareto, Weber, Schumpeter e Lênin.

Observemos que, de modo dominante, a democracia representativa se justifica, mesmo entre os defensores da democracia direta, pelo tamanho das 
populações e, por vezes, pela complexidade dos assuntos que parecem gerar a necessidade de especialistas ou de tempo para seu estudo. Vejamos como exemplos o pré-sal e o projeto de Belo Monte. Sua complexidade os coloca distante da discussão informada dos cidadãos da rua e do tempo de que dispõem para nela se aprofundar.

A comunicação mediada foi e ainda é vista, predominantemente, como estando nas mãos dos poderosos no plano de como as coisas são, mesmo quando a ética jornalística insiste sobre sua função de expor a verdade, de denunciar e de controlar os poderosos, agora no plano de como as coisas deveriam ser. Todavia, não podemos deixar de mencionar que a emergência da internet e de um mundo em rede reavivou as propostas de democracia direta e que, no intuito de não perder as vantagens de ambas e de compensar seus defeitos, nossos legisladores introduziram formas de democracia direta no governo representativo (como exemplos, plebiscito e iniciativa popular). Embora razões práticas impossibilitem a democracia direta, a preferência por ela e o sonho de sua vigência continuam fortíssimos. Creio que os emancipacionistas partilham o sonho da democracia direta: ela seria mais justa, mais bela e verdadeira.

As críticas políticas à naturalidade e universalidade da divisão política foram e são paralelas às críticas à divisão social do trabalho entre proprietários e trabalhadores ou entre diretores e dirigidos; à divisão na educação entre os que sabem e os que aprendem ou entre os donos do saber e os aprendizes. Os emancipacionistas foram também críticos à divisão, no campo da cultura e das artes, entre produtores e consumidores; à divisão, no campo da comunicação, entre emissores e receptores. Grande parte das apostas na interatividade das novas tecnologias de comunicação tem como principal objetivo superar a divisão entre emissores ativos e receptores passivos. Como tais críticas às divisões são velhas e reiteradas, cada leitor pode evocar vários exemplos. Peço que lembrem especialmente as que circularam e circulam no campo da educação física e, sobretudo, a visão dos esportes enquanto espetaculares, bloqueadores da participação de todos, ou da inclusão, e geradores da não-atividade e da falta de criatividade no público.

Pessoalmente, creio que Bertolt Brecht deveria ocupar um lugar de destaque com sua proposta de superação da divisão que, no campo do teatro, foi formulada lá pela década de 1920. Embora sua proposta tenha quase um século de vida, ela continua sendo recorrentemente rememorada e citada. Recentemente, lendo propostas de interatividade comunicacional, a partir das novas tecnologias, sobretudo da televisão digital, deparei-me de novo com a menção dos desejos brechtianos de superação da divisão no campo do teatro, como exemplar para outros campos. Alguns autores propõem, por exemplo, que a participação do público possa modificar os roteiros, a trama, da novela televisiva. Não ficam muito claros os motivos que o assistente televisivo teria para se converter em coautor; contudo, supõe-se que ele deseja isso e, mesmo que não seja um desejo ou vontade, sua participação deverá ser viabilizada para 
provocar um salto, de baixo para alto grau de interatividade ${ }^{1}$. Ou seja, de interatividades fracas, como a do Big Brother, para interatividades fortes, ao Brecht Brother. Em outras palavras, para uma participação ativa e, talvez, criativa. Participação, atividade e criatividade são valores fortes no discurso democrático, na defesa do desenvolvimento inclusivo e sustentável, no campo educacional e em quase todas as áreas de atividade social. Em vários aspectos, esses valores fazem parte do núcleo partilhado e demandado do agir na modernidade. No entanto, apesar do consenso, suas realizações não parecem ser suficientes para satisfazer sua vigorosa demanda.

A resistência mediante a "saída", mecanismo de mercado explorado por Hirschman (1973), ao desligar a televisão ou não ir ao espetáculo, é vista pelos autores como uma interatividade fraca, embora seja ela a que mais preocupa os donos do negócio, atentos aos índices de televisores ligados. Para os comunicadores, a interatividade seria forte se o espectador escolhesse o ângulo, o recorte da câmera preferida entre todas as câmeras. Reconheço que, pessoalmente, se tivesse que comparar a imagem de mais de vinte câmeras para escolher aquela pela qual pretendo ver um jogo, perderia a partida. Isso de fato também ocorre quando estamos no estádio de futebol; certas áreas e jogadas escapam ao nosso poder de visão e compreensão e, por vezes, sabemos o que ocorreu pela leitura do movimento coletivo do corpo dos que estão em boa posição nas arquibancadas.

Confesso que me custa entender o que pretendem os comunicólogos com a interatividade. Seus argumentos ou bem me parecem irrealizáveis, ou totalmente distantes dos meus interesses de espectador, que, por certo, podem ser diferentes dos de outros participantes. Os promotores do Brecht Brother estariam tentando eliminar a diferença entre esses dois interesses? Deveríamos nos tornar participantes-espectadores ou espectadores-participantes? A redução dos interesses aponta para o sonho da unidade quebrada na crescente complexidade ou pluralidade social e cultural?

É importante destacar que os donos dos meios de comunicação olham para a interatividade com um misto de esperança e desânimo. Esperança na interatividade para novos e rentáveis negócios; desânimo porque não parece fácil encontrar os caminhos para realizar a esperança. Para os donos do negócio da comunicação, a interatividade não parece possuir nenhum caráter revolucionário nem contestador. É apenas mais uma possibilidade de negócios, por ora de difícil realização. Assim, a interatividade, como a democracia direta, é excelente, contudo pouco prática.

1 São notórios os mecanismos por meio dos quais as emissoras de televisão acompanham, avaliam e modificam seus programas. No caso do Brasil, são conhecidas mudanças provocadas a partir de acompanhamentos informais e formais. Estes efeitos da vontade do público sobre a programação, contudo, não poderiam ser confundidos com uma intervenção que habitualmente se especifica como "interatividade". 


\section{ARRANJOS ESPORTIVOS: PARTICIPAÇÃO, CAPITAL SOCIAL E CONFIANÇA}

O crescimento dos megaeventos esportivos, entretanto, parece estar nos dizendo: "nós, público, gostamos de ser espectadores, presenciais ou midiáticos, e não nos incomodamos nem nos sentimos diminuídos por ocupar esse papel tão desvalorizado pelos críticos da divisão. Mais ainda, não estamos nem aí para as críticas e adoramos a competição excitante, sociologicamente conceituada por Norbert Elias e colaboradores". Parece, então, que estamos mais do lado do Big Brother do que do Brecht Brother.

Contudo, creio que há um núcleo no pensamento emancipacionista ou iluminador que merece ser mais bem refinado. Segundo o ponto de vista crítico, no campo do espetáculo os assistentes são vistos como não-ativos, não-participativos e não-criativos diante do agir dos profissionais do espetáculo. Em oposição, postula-se que a superação da divisão geraria a atividade, a participação e a criatividade. Esses valores, de clara tradição romântica, são postos como evidências para a crítica da divisão. Ou seja, entende-se que eles são bons, justos e talvez até belos e deveriam ser perseguidos e alcançados por todos. $\mathrm{Na}$ realização desses valores obteríamos tanto uma sociedade melhor quanto indivíduos realizados, desenvolvidos, adultos. Não posso deixar de apontar que esses argumentos se aproximam muito dos que defendem o valor superior da democracia direta. Em ambos os casos se trata da valorização da "liberdade para" agir ou liberdade positiva, para construir, realizar e não apenas usufruir os direitos da "liberdade de" podermos escolher livres de opressão, de nos realizarmos na liberdade dos modernos, a privada ou liberdade negativa. Evidentemente, tenho em mente as contribuições de Rousseau e Benjamin Constant, cuja conceituação refinou Isahiah Berlin (1981).

Nas atuais teorizações sobre desenvolvimento (regional, local, da cidade e até da nação), cresce o destaque ao denominado capital social, traduzido e indicado pelas redes de relações, e o lugar que ocupa a "confiança", que também pode ser entendida como coesão, enquanto base dos relacionamentos. Os autores que se ocupam do tema distinguem dois movimentos: o centrípeto ou confiança interna; e o centrífugo ou confiança externa. Interna seria, principalmente, a confiança na família e na religião, ou seja, no que alguma vez chamamos de relações primárias em oposição às secundárias; a externa seria responsável por estender pontes e alongar as esferas do agir em comum. A confiança, sobretudo a segunda, é vista como capital social, no sentido estrito de fator de produção do desenvolvimento social, que permite a formação de arranjos produtivos, a integração, o agir em conjunto dos produtores interessados junto aos outros segmentos e, portanto, a cooperação. A formação e a atividade das redes, diretas ou mediadas, são vistas como a manifestação ou prática da confiança social que se expressaria nas categorias de "partilhar" e "compartilhar". Embora os conceitos de capital social e confiança social, com esse ou outros nomes, tenham uma história de vários séculos, as novas tec- 
nologias, de modo geral, e as redes sociais, de modo particular, deram alento aos defensores da hipótese do lugar estratégico do capital social no desenvolvimento. Os argumentos e as provas empíricas sobre as relações em pauta são suficientemente sólidos para prestarmos atenção à formação do capital social mediante o desenvolvimento da confiança e ao impacto sobre o desenvolvimento social, caracterizado por valores como sustentabilidade e inclusão.

As teorizações estão nos dizendo que o desenvolvimento não é apenas capital financeiro, inovação tecnológica e capacitação dos trabalhadores. Dizem que há alguma coisa a mais que explica ou contribui para explicar as diferenças entre o que se desenvolve e o que fica atrasado. A educação, observada segundo o nível de escolaridade, seria uma variável positivamente associada à confiança externa e, portanto, ao capital social que promoveria acordos, arranjos, cooperação e, de modo geral, a interação entre diferentes agentes para elaborar e perseguir objetivos em comum. Tudo isso fica muito claro nas explicações sobre o desenvolvimento local e sobre a formação de clusters produtivos, entre outros arranjos ou acordos. Estabelecer acordos, que demandam confiança ou sua criação no diálogo, para criar formas organizacionais que funcionem como recurso para se atingirem objetivos, é um eixo do desenvolvimento em qualquer dimensão social.

\section{OS CLUBES SOCIAIS E ESPORTIVOS}

Dentre as formas organizacionais criadas de baixo para cima, os clubes - esportivos e sociais ou sociais e esportivos - tiveram grande desenvolvimento desde o século XIX. Mesmo nos países ditos subdesenvolvidos, a capacidade de construir a forma organizacional "clube" para atingir objetivos de lazer e sociabilidade, para realizar, a meu ver, atividades antitédio (Lovisolo, 2002), foi significativa, dando lugar à sua multiplicação. No bairro em que moro existem mais clubes surgidos de baixo para cima do que escolas ou igrejas construídas de cima para baixo. Há alguns anos, Wanderlei G. dos Santos, estudando as associações ou organizações no Brasil, apontou a expressividade numérica dos clubes no conjunto das associações. Hoje se destaca, por exemplo, a capacidade de organização de eventos da Fifa, do COI e da ATP, que se baseiam em arranjos de interesses e participação de instâncias de governos e de numerosas organizações privadas. E significativo que os arranjos permitam atender interesses diferenciados mediante a realização dos eventos e que isto ocorra apenas por se estabelecerem níveis de confiança funcionais entre os parceiros. No caso do esporte, uma dimensão significativa da confiança reside no respeito às regras e na expectativa da sanção quando elas são quebradas.

No campo dos estudos e pesquisas das ciências sociais e da comunicação sobre o esporte, sua relação com a identidade nacional, regional e a sociabilidade foi longamente trabalhada. No caso do Brasil, o futebol concentrou as atenções enquanto formador da identidade nacional, na companhia do sam- 
ba e do carnaval, e como agregador de vontades individuais, tanto no ato de jogar quanto no de torcer pelo clube. Ao longo do século XX, funcionou como um objeto totêmico adequado para pensar tanto os defeitos quanto as virtudes do caráter ou ser nacional brasileiro. Roberto DaMatta, no Brasil, enfatizou a vitalidade teórica das relações entre sociedade e futebol e futebol e sociedade. Ousadamente, Foer (2005) procurou explicitar "como o futebol explica o mundo". Houve um tempo em que se desconfiava da têmpora e da confiança em si mesmo dos esportistas brasileiros. O tema da confiança jamais esteve ausente.

À medida que o esporte foi ganhando destaque e o Brasil foi se tornando o país do futebol juntamente com o reconhecimento e a valorização de seus heróis, virtudes como raça e esperteza ganharam positivo destaque, inclusive em outros esportes. A "raça", esse valor tão admirado na tradição do futebol do Uruguai, está incorporada e é elogiada no discurso jornalístico; quando ausente, surge em sua crítica. Porém, são elogiados também valores como disciplina, dedicação, capacidade de comunicação intraequipe e o aprender dos outros (difusão técnica e táctica). Parecem atitudes difíceis de serem desenvolvidas sem a confiança nas instituições, nos técnicos e, sobretudo, nos companheiros. A confiança fundamenta o andar e o apreender juntos.

No pequeno e complexo mundo do time esportivo, a confiança em si mesmo é fundamental quando temperada pela consciência das próprias limitações, pois, sem isso, se torna arrojo que não mede as consequências. Contudo, quando se enfatiza o jogo de equipe, se alude a valores como cooperação e, deste ponto de vista, a competição supõe a cooperação no campo do esporte, que por sua vez supõe a confiança. A cooperação só pode existir sob a base da confiança no outro. Por certo, uma confiança informada, limitada e criada no treino. Tenho a impressão de que ainda estaríamos no campo da confiança para "dentro". Creio que essa confiança pode e deve ser desenvolvida na equipe e talvez seja um objetivo central do treinamento coletivo (Lovisolo; Lacerda, 1999).

Minha questão é: e a confiança para fora, externa ou ponte, como ela poderia ser desenvolvida?

\section{MEGAEVENTOS E CONFIANÇA}

A organização de eventos como a copa do mundo de futebol e os jogos olímpicos poderia constituir um caminho de desenvolvimento da confiança externa, daquela que nos permite agir em comum? Sua realização deixaria a mensagem de que quando agimos baseados na confiança podemos promover eventos significativos? Seria o desenvolvimento da confiança externa um efeito intangível que merece ser procurado e expandido nos eventos esportivos? $\mathrm{O}$ evento demanda níveis significativos de confiança e sua realização realimentaria a confiança em nós mesmos? A confiança se tornou lugar comum nas declarações 
dos políticos responsáveis nos diferentes níveis da organização política brasileira, sobretudo do ex-presidente ao prefeito.

Posso agora colocar as propostas críticas dos emancipacionistas no contexto da formação do capital social. Seriam a participação e a criatividade formas de aumentar a confiança interna e externa? Minha resposta seria naturalmente afirmativa: para participar e criar são necessários os outros, e como fazê-lo se neles não confiarmos! Na verdade, a capacidade de participar e criar, ou meramente participar, está na base do trabalho voluntário, que pode ser entendido como o núcleo tradicional e prático do capital social. Por essa razão, quando se pesquisa a confiança e o capital social se interroga sobre a participação local no trabalho voluntário. Considera-se que os Estados Unidos, por exemplo, são um país no qual o trabalho voluntário contribuiu para seu crescimento e, sobretudo, para seu desenvolvimento social. O Open de Tênis é fortemente apresentado como um evento baseado no trabalho voluntário, significando, portanto, sua valorização.

Contudo, teríamos que romper com a imagem de que a única participação válida é a do autor, do artista, do ator ou do atleta. Não participam apenas os que estão sob as luzes dos holofotes ou no campo, nas pistas, nas piscinas ou nas quadras. A participação dos artesãos que criam o objeto deve ser salientada e valorizada, e não apenas a originalidade do artista. A ideia de cooperação é difícil de ser sustentada sob o ponto de vista da originalidade pessoal ou individual, pois ela habita na qualidade do trabalho coletivo. A originalidade é a marca do artista, do autor e do esportista, e não necessariamente das centenas de artesãos que possibilitaram as condições para o exercício da originalidade. A Wikipédia que todos nós usamos não é original sob o ponto de vista do produto, nem de sua qualidade: ela é original porque resulta de um trabalho voluntário e cooperativo que cria um capital social significativo. A originalidade, em contrapartida, demanda deslocar o foco para o evento: as olimpíadas são originais (Barcelona, Moscou, Beijing, entre outras).

\section{CONSIDERAÇÕES FINAIS}

Creio que temos duas tarefas. A primeira seria a de acompanhar o processo da confiança externa antes e depois dos dois grandes megaeventos que temos pela frente no Brasil. Um modelo que parece interessante e que já constitui uma base comparativa é a Pesquisa de Coesão Social na América Latina (EcoSocial) realizada pela Cieplan (Cooperación de Estudios para Latinoamérica) ${ }^{2}$. A segunda tarefa é a de insistir e arbitrar os meios para que o trabalho voluntário se torne uma realidade de peso nos megaeventos, não apenas do ponto de vista de sua utilização generalizada, mas também e fundamentalmente do de sua divulgação para o conjunto da sociedade.

2 Ver: <http://www.cieplan.org $>$. 
As áreas da educação física e da comunicação social, em conjunto, podem desempenhar um papel estratégico em ambas as tarefas. Seria muito importante se passássemos a pensar de forma sistemática, sobretudo nas pós-graduações, as relações entre a comunicação, o esporte e a confiança social. Todavia, mais importante parece ser a tarefa de desenvolver a confiança social e suas redes. Esse tema parece ser mais relevante para o futuro do que o das relações entre esporte e identidade, aparentemente já esgotadas ou com poucas possibilidades de inovarmos.

O investimento em rede parece ser um bom pontapé inicial para abrirmos o jogo. Sobretudo quando se partilha a convicção de que a confiança é uma força primordial no desenvolvimento social. O entendimento dos efeitos intangíveis no campo do desenvolvimento da confiança e, portanto, do capital social, deve passar a fazer parte da agenda de compromisso social dos que apostam em um mundo melhor. Os comunicadores têm uma porção significativa dessa responsabilidade.

\section{REFERÊNCIAS}

BERLIN, Isaiah. Quatro ensaios sobre a liberdade. Brasília: Ed. UNB, 1981.

CEPAL. Cohesión social, inclusión y sentido de pertenencia en América Latina y el Caribe. Santiago: Cepal, 2007.

DEBORD, Guy. La societé du spectacle. Paris: Galimard, 1992.

FOER, Franklin. Como o futebol explica o mundo. Rio de Janeiro: J. Zahar Editor, 2005.

HIRSCHMAN, Albert As paixões e os interesses. Rio de Janeiro: Paz e Terra, 1973.

LOVISOLO, Hugo R; LACERDA, Yara. Reencantando as quadras: basquete e espiritualidade. Revista Estudos Históricos, Rio de Janeiro, FGV, v. 1, n. 23, p. 73-86, 1999.

LOVISOLO, Hugo R. Mídia, lazer e tédio. Intercom - Revista Brasileira de Ciências da Comunicação, São Paulo, v. XXV, n. 2, jul./dez. 2002.

PATULNY, Roger V.; SVENDSEN, Gunnar L. H. Exploring the social capital grid: bonding, bridging, qualitative, quantitative. International Journal of Sociology and Social Policy, v. 27, n. 1/2, p. 32-51, 2007.

PUTNAM, Robert D. Comunidade e democracia: a experiência da Itália moderna. Rio de Janeiro: Ed. FGV, 1996. . Bowling alone: the collapse and revival of American community. New York: Touchstone, 2001. El declive del capital social. Barcelona: Ed. Galaxia Gutemberg / Círculo de Lectores, 2003. 